\title{
Anxiety sensitivity, fear of pain and pain-related disability in children and adolescents with chronic pain
}

\author{
Andrea L Martin $M A^{1,2}$, Patricia A McGrath $\mathrm{PhD}^{1,2,3}$, Stephen C Brown $M D^{1,3}$, Joel Katz $\mathrm{PhD}^{2,3}$
}

\begin{abstract}
AL Martin, PA McGrath, SC Brown, J Katz. Anxiety sensitivity, fear of pain and pain-related disability in children and adolescents with chronic pain. Pain Res Manage 2007;12(4):267-272.
\end{abstract}

BACKGROUND: Converging lines of evidence suggest that anxiety sensitivity and fear of pain may be important vulnerability factors in the development of avoidance behaviours and disability in adults with chronic pain. However, these factors have not been evaluated in children with chronic pain.

OBJECTIVES: To examine the relationships among anxiety sensitivity, fear of pain and pain-related disability in children and adolescents with chronic pain.

METHODS: An interview and five questionnaires (Childhood Anxiety Sensitivity Index, Pain Anxiety Symptoms Scale, Functional Disability Inventory, Multidimensional Anxiety Scale for Children, and Reynolds Child or Adolescent Depression Scale) were administered to 21 children and adolescents eight to 17 years of age (mean \pm SD $14.24 \pm 2.21$ years) who continued to experience pain an average of three years after discharge from a specialized pain clinic for children.

RESULTS: Anxiety sensitivity accounted for $38.6 \%$ of the variance in fear of pain $(F[1,20]=11.30 ; \mathrm{P}=0.003)$ and fear of pain accounted for $39.9 \%$ of the variance in pain-related disability $(F[1,20]=11.95$; $\mathrm{P}=0.003)$, but anxiety sensitivity was not significantly related to pain disability $\left(R^{2}=0.09 ; P>0.05\right)$.

CONCLUSIONS: These findings indicate that children with high levels of anxiety sensitivity had a higher fear of pain, which, in turn, was linked to increased pain disability. The results of this study suggest that anxiety sensitivity and fear of pain may play important and distinct roles in the processes that maintain chronic pain and painrelated disability in children.

Key Words: Anxiety sensitivity; Children; Chronic pain; Disability; Fear of pain

\section{La sensibilité à l'anxiété, la crainte de la douleur et l'invalidité reliée à la douleur chez des enfants et des adolescents atteints de douleur chronique}

\begin{abstract}
HISTORIQUE : D'après des sources de données convergentes, la sensibilité à l'anxiété et la crainte de la douleur peuvent être des facteurs de vulnérabilité importants dans le développement de comportements d'évitement et d'invalidités chez des adultes atteints de douleurs chroniques. Cependant, on n'a pas évalué ces facteurs chez les enfants atteints de douleurs chroniques.

OBJECTIFS : Examiner les liens entre la sensibilité à l'anxiété, la crainte de la douleur et l'invalidité reliée à la douleur chez les enfants et les adolescents atteints de douleur chronique.

MÉTHODOLOGIE : On a fait passer une entrevue et cinq questionnaires (indice de sensibilité à la douleur pendant l'enfance, échelle des symptômes d'anxiété de la douleur, inventaire des invalidités fonctionnelles, échelle d'anxiété multidimensionnelle pour les enfants et échelle Reynolds de dépression des enfants et des adolescents) à 21 enfants et adolescents de huit à 17 ans (âge moyen $\pm E ́ T$ 14,24 $\pm 2,21$ ans) qui continuaient de ressentir des douleurs en moyenne trois ans après leur congé d'une clinique pour enfants spécialisée dans la douleur.

RÉSULTATS : La sensibilité à l'anxiété représentait 38,6 \% de la variance de crainte de la douleur $(\mathrm{F}[1,20]=11,30 ; \mathrm{P}=0,003)$ et la crainte de la douleur, 39,9 \% de la variance d'invalidité reliée à la douleur $(\mathrm{F}[1,20]=11,95 ; \mathrm{P}=0,003)$, mais la sensibilité à l'anxiété n'avait pas de relation significative avec l'invalidité reliée à la douleur.

CONCLUSIONS : Selon ces observations, les enfants ayant un taux élevé de sensibilité à l'anxiété craignaient davantage la douleur, ce qui s'associait à une augmentation de l'invalidité reliée à la douleur. Les résultats de cette étude indiquent que la sensibilité à l'anxiété et la crainte de la douleur jouent peut-être un rôle important et ont peut-être des rôles distincts dans les processus de maintien de la douleur chronique et de l'invalidité reliée à la douleur chez les enfants.
\end{abstract} Pediatric chronic pain conditions are associated with female
sex, increased age $(1,2)$, anxiety and depression (3), but the risk factors for developing ongoing pain and disability remain largely unknown. In adults, anxiety sensitivity has been proposed as a critical factor in the maintenance of chronic pain (4). Individuals high in anxiety sensitivity fear anxiety-related sensations, such as a rapidly beating heart, believing that these physical sensations will have harmful consequences (5). From a cognitive-behavioural perspective, a cyclical pattern of thoughts and behaviours has been proposed to develop, in which individuals high in anxiety sensitivity are thought to be at greater risk of developing fear of pain (4). Because these individuals are more likely to fear the consequences of pain sensations, they are also more likely to avoid them (eg, restrict pain-inducing activities), which subsequently results in disability and enhanced fear experiences, initiating renewed fear of pain and avoidance behaviours $(4,6,7)$.

Converging lines of evidence support a fear-avoidance model involving anxiety sensitivity for several adult chronic pain conditions, including headache $(8,9)$, low back pain $(10)$ and musculoskeletal pain (11). Research has shown a moderate correlation $(r=0.32$ to $r=0.62)(10)$ between scores on the Anxiety Sensitivity Index (12) and subscales of the Pain Anxiety Symptoms Scale for adults (13). Furthermore, anxiety

${ }^{1}$ Department of Anesthesia, Divisional Centre for Pain Management and Research, The Hospital for Sick Children; ${ }^{2}$ Department of Psychology, York University; ${ }^{3}$ Department of Anesthesia, The University of Toronto, Toronto, Ontario

Correspondence and reprints: Ms Andrea Martin, Department of Psychology, Behavioural Sciences Building, York University, 4700 Keele Street,

Toronto, Ontario M3J 1P3. Telephone 416-736-2100 ext 33125, e-mail amartin@yorku.ca 


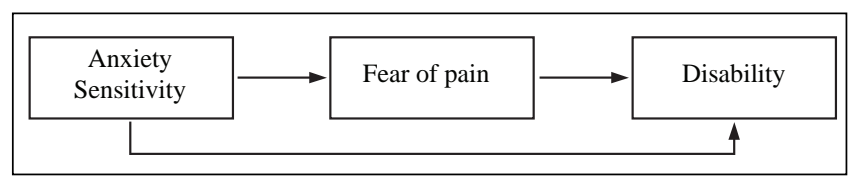

Figure 1) Hypothesized relationships among anxiety sensitivity, fear of pain and disability

sensitivity predicts fear of pain better than depression or pain severity for adults with chronic pain (14). Research also indicates that fear of pain is a strong predictor of disability (13), as well as restricted range of motion during a passive straight leg raise test in individuals with chronic back pain (15).

The theory that anxiety sensitivity exacerbates fear of pain and, as a result, pain-specific avoidance behaviours has empirical support in several adult chronic pain populations $(8,10,11)$. More recently, aspects of this model have been examined in healthy youth (16) and children (17), demonstrating a significant relationship between anxiety sensitivity and fear of pain. However, research has yet to examine whether these relationships are evident among children with chronic pain.

The present study examined the relationships among anxiety sensitivity, fear of pain and disability in children and adolescents with chronic pain. Specifically, this study tested the hypothesis that fear of pain mediates the relationship between anxiety sensitivity and disability (Figure 1). A mediation model is suggested by adult literature indicating that anxiety sensitivity indirectly influences avoidance via its effects on fear of pain (11) and also offers the most parsimonious relationship among these three variables. Furthermore, we examined whether the relationships among these variables persist after controlling for anxiety, depression, age, sex and pain intensity.

\section{Participants}

\section{PARTICIPANTS AND METHODS}

Participants were recruited from a cohort of children who had been identified with continuing pain during clinic follow-up (18). The sample comprised 21 children and adolescents (16 female and five male patients) aged eight to 17 years (mean \pm SD $14.24 \pm 2.21$ years) who continued to experience pain an average of three years after discharge from the chronic pain clinic at The Hospital for Sick Children (Toronto, Ontario). Table 1 shows the type and frequency of the primary diagnosis at the initial assessment in the chronic pain clinic. Follow-up ranged from two to five years (mean \pm SD $3.46 \pm 0.92$ years).

\section{Measures and procedure}

Informed consent (or child assent) was obtained from all participants and their parent or guardian before their participation in the study. After signed consent was obtained, a brief, structured interview (approximately $10 \mathrm{~min}$ in length) was completed in person with both parent and child to obtain information about the child's pain history since they were discharged from the clinic. During this interview, participants were asked to rate the intensity of their current pain on a 0 to 10 numerical rating scale.

After the interview, participants completed the following questionnaires: the Childhood Anxiety Sensitivity Index (CASI) (19), a simplified version of the Pain Anxiety Symptoms Scale (PASS) (20), the Functional Disability Inventory (FDI) (21), the Multidimensional Anxiety Scale for Children (MASC)
TABLE 1

Primary diagnosis after initial assessment in the chronic pain clinic

\begin{tabular}{lcc}
\hline Diagnosis & $\mathbf{n}$ & $\%$ \\
\hline Abdominal pain - identified disease & 1 & 4.76 \\
Abdominal pain - recurrent & 2 & 9.52 \\
Chronic pain and disability & 2 & 9.52 \\
Chronic regional pain syndrome type 1 & 4 & 19.05 \\
Headache - chronic daily & 2 & 9.52 \\
Musculoskeletal - identified disease & 2 & 9.52 \\
Musculoskeletal - idiopathic & 2 & 9.52 \\
Musculoskeletal - postinfectious & 2 & 9.52 \\
Musculoskeletal - postsurgical & 2 & 9.52 \\
Neuromuscular - identified disease & 2 & 9.52 \\
Total & 21 & 100.00 \\
\hline
\end{tabular}

(22), and the Reynolds Child Depression Scale (RCDS) or Reynolds Adolescent Depression Scale (RADS) $(23,24)$.

\section{CASI}

The CASI is an 18-item self-report scale that measures anxiety sensitivity in school-aged children. Sample items include: "It scares me when my heart beats fast" and "I don't want other people to know when I feel afraid". Children are asked to rate their experience of anxiety symptoms by answering either "none" (1), "some" (2) or "a lot" (3) to each item. The child's total anxiety sensitivity score is the sum of the 18 items. Thus, scores on the CASI can range from 18 to 54 . The scale has been shown to have good internal consistency $(\alpha=0.87)$ and good test-retest reliability $(\mathrm{r}=0.76)(19)$.

\section{PASS-20}

The PASS-20 is a shortened, 20-item version of the original PASS (13) designed to assess fear and anxiety responses specific to pain. The PASS-20 consists of four five-item scales measuring cognitive anxiety, escape and avoidance responses, fearful thinking and physiological anxiety responses. Each item is rated on a frequency scale from "never" (0) to "always" (5), with total scores ranging from 0 to 100 . The PASS-20 has been shown to have good internal consistency $(\alpha=0.81)$, good convergent validity with the original PASS-40 $(r=0.95)$ and good construct validity (20). For the purposes of the present study, a modified, age-appropriate version of the PASS-20 was used. Items containing difficult language were reworded to a level appropriate for eight- to 17-year-olds. For example, item 1 on the adult PASS-20 - "I think that if my pain gets too severe, it will never decrease" - was changed to "I think that if my pain gets too bad, it will never get better". The modified version of the PASS used in the present study demonstrated good internal consistency $(\alpha=0.89)$.

\section{FDI}

The FDI is a 15 -item self-report scale designed to measure the degree of difficulty a child reports when engaging in certain activities as a result of feeling sick or unwell. Each item is scored on a scale from "no trouble" (0) to "impossible" (4), with total scores ranging from 0 to 60 . The FDI has been shown to have good internal consistency $(\alpha=0.90)$ and good concurrent validity, as demonstrated by the high correlation between child and parent forms of the FDI $(\mathrm{r}=0.71)$ (21). The FDI is a frequently 
TABLE 2

Patient variables and questionnaire score results

\begin{tabular}{lccc}
\hline Measure & $\begin{array}{c}\text { Total } \\
(\mathbf{n = 2 1 )}\end{array}$ & $\begin{array}{c}\text { Girls } \\
(\mathbf{n = 1 6 )}\end{array}$ & $\begin{array}{c}\text { Boys } \\
(\mathbf{n = 5})\end{array}$ \\
\hline Pain intensity (0 to 10) & $6.8 \pm 1.4$ & $6.4 \pm 1.3$ & $7.9 \pm 1.0$ \\
Age, years & $14.2 \pm 2.2$ & $14.4 \pm 2.3$ & $13.8 \pm 2.2$ \\
Childhood Anxiety Sensitivity Index & $31.2 \pm 6.2$ & $31.9 \pm 6.4$ & $29.2 \pm 5.3$ \\
Pain Anxiety Symptoms Scale-20 & $48.5 \pm 20.8$ & $53.9 \pm 18.4$ & $32.0 \pm 20.4$ \\
$\begin{array}{l}\text { Functional Disability Inventory } \\
\text { Multidimensional Anxiety Scale for }\end{array}$ & $22.2 \pm 17.9$ & $25.8 \pm 18.7$ & $10.6 \pm 8.4$ \\
$\quad$ Children & $49.1 \pm 13.3$ & $50.3 \pm 13.2$ & $45.2 \pm 14.3$ \\
RADS/RCDS & $58.8 \pm 16.1$ & $61.9 \pm 16.5$ & $48.8 \pm 10.8$
\end{tabular}

All data presented as mean $\pm S D$. RADS Reynolds Adolescent Depression Scale; RCDS Reynolds Child Depression Scale

used measure of disability in pediatric chronic pain populations, including those with fibromyalgia (25), recurrent abdominal pain (26), juvenile rheumatoid arthritis (27), chronic back pain (28) and complex regional pain syndrome (3).

\section{MASC}

The MASC is a widely used 39-item self-report scale designed to measure symptoms of anxiety in children and adolescents eight to 19 years of age. The MASC has four subscales measuring physical symptoms, social anxiety, harm avoidance and separation anxiety. The MASC has been shown to have good internal consistency ( $\alpha=0.60$ to $\alpha=0.85$ ) and high test-retest reliability ( $\mathrm{r}=0.79$ to $\mathrm{r}=0.93$ ), as well as good convergent validity, as illustrated by its significant correlation with other measures of anxiety (Revised Children's Manifest Anxiety Scales), and discriminant validity, as illustrated by its lack of a significant correlation with measures of depression (Children's Depression Inventory) and disruptive behaviour (Abbreviated Symptom Questionnaire - Parents) (22).

\section{RCDS}

The RCDS is a 30-item self-report measure designed to assess symptoms of depression in children eight to 12 years of age. The RCDS has been shown to have high internal consistency ( $\alpha=0.88$ to $\alpha=0.92$ ) and high test-retest reliability ( $r=0.85)$, as well as high convergent $(\mathrm{r}=0.72)$ and concurrent $(\mathrm{r}=0.84)$ validities (23).

\section{RADS}

The RADS is the adolescent equivalent of the RCDS. The RADS is designed for individuals 11 to 20 years of age, and differs from the child version in that the 30-item measure has four subscales: dysphoric mood, anhedonia or negative affect, negative self-evaluation and somatic complaints. Similar to the child depression scale, the RADS has been shown to have high internal consistency $(\alpha=0.93)$ and high test-retest reliability $(r=0.85)$, as well as good convergent validity $(r=0.56$ to $r=0.77)(24)$.

\section{Descriptive statistics}

\section{RESULTS}

Means and SDs for each of the variables are presented in Table 2. Anxiety sensitivity scores were elevated for the sample as a whole compared with a nonclinical sample of children $(\mathrm{n}=81$; mean \pm SD 26.53 \pm 5.81$)$ (19). Overall, disability scores were in the moderate to high range (FDI greater than 10) (25), and participants reported high mean pain intensity ratings on
TABLE 3

Zero-order correlations among variables $(n=21)$

\begin{tabular}{lllllllll}
\hline & $\mathbf{1}$ & $\mathbf{2}$ & $\mathbf{3}$ & $\mathbf{4}$ & $\mathbf{5}$ & $\mathbf{6}$ & $\mathbf{7}$ & $\mathbf{8}$ \\
\hline 1. CASI & 1.0 & - & - & - & - & - & - & - \\
2. PASS-20 & $0.62^{\star *}$ & 1.0 & - & - & - & - & - & - \\
3. FDI & 0.31 & $0.63^{\star *}$ & 1.0 & - & - & - & - & - \\
4. MASC & $0.56^{* *}$ & $0.59^{* *}$ & $0.53^{*}$ & 1.0 & - & - & - & - \\
5. RADS/RCDS & $0.48^{*}$ & $0.48^{*}$ & 0.40 & $0.75^{* *}$ & 1.0 & - & - & - \\
6. Pain intensity & 0.22 & -0.04 & -0.26 & -0.05 & -0.17 & 1.0 & - & - \\
7. Sex & -0.19 & $-0.47^{*}$ & -0.37 & -0.17 & -0.36 & $0.47^{*}$ & 1.0 & - \\
8. Age & 0.26 & -0.17 & 0.04 & 0.05 & 0.17 & -0.16 & -0.11 & 1.0 \\
\hline
\end{tabular}

${ }^{*} P<0.05,{ }^{*} P<0.01$. CASI Childhood Anxiety Sensitivity Index; FDI Functional Disability Inventory; MASC Multidimensional Anxiety Scale for Children; PASS-20 Pain Anxiety Symptoms Scale-20; RADS Reynolds Adolescent Depression Scale; RCDS Reynolds Child Depression Scale

a 0 to 10 numeric rating scale. Fear of pain scores were higher than those observed in an adult chronic pain population (mean \pm SD PASS-20 score 38.62 \pm 20.38 ) (20). However, anxiety and depression scores were within the normal range. Correlation coefficients are presented in Table 3. Age and pain intensity were not significantly correlated with any of the questionnaire scores.

\section{Relationships among anxiety sensitivity, fear of pain and} pain-related disability

A series of linear regression analyses was used to examine the relationships between anxiety sensitivity and fear of pain; fear of pain and pain-related disability; and anxiety sensitivity and painrelated disability. The hypothesis that fear of pain mediates the relationship between anxiety sensitivity and pain-related disability was assessed using procedures for testing mediation outlined by Baron and Kenny (29). In general, a variable may be considered a mediator when it accounts for the relationship between a dependent and an independent variable. To demonstrate the proposed mediation model, four conditions had to be met: first, anxiety sensitivity must predict fear of pain; second, fear of pain must predict pain-related disability; third, anxiety sensitivity must predict pain-related disability; and fourth, the relationship between anxiety sensitivity and pain-related disability must be significantly reduced when fear of pain was included in the mod$\mathrm{el}$, thereby revealing fear of pain as a mediator.

To test the mediation model, linear regression analysis was first conducted with CASI total score as the predictor variable and PASS-20 total score as the dependent variable. Results indicated that anxiety sensitivity accounted for $38.6 \%$ of the variance in fear of pain $(\mathrm{F}[1,20]=11.30 ; \mathrm{P}=0.003)$. The relationship between fear of pain and pain-related disability was examined next. Linear regression analysis indicated that fear of pain accounted for $39.9 \%$ of the variance in pain-related disability $(\mathrm{F}[1,20]=11.95 ; \mathrm{P}=0.003)$. Having satisfied the first two conditions for testing mediation, the relationship between anxiety sensitivity and pain-related disability was then tested. Results of this analysis showed that anxiety sensitivity was not a significant predictor of pain-related disability $\left(R^{2}=0.09\right.$; $F[1,20]=1.96 ; P=0.18)$. Failing to meet the third condition, the present results did not support the proposed mediation model. Nevertheless, the results indicate that anxiety sensitivity is a significant predictor of fear of pain and that fear of pain is a significant predictor of pain disability. A power analysis indicated that the final regression analysis, with $\mathrm{R}^{2}=0.09$, had a 
TABLE 4

Summary of hierarchical regression analysis for variables predicting fear of pain $(n=21)$

\begin{tabular}{lcccc}
\hline Variable & $\boldsymbol{\beta}$ & SE $\boldsymbol{\beta}$ & $\boldsymbol{t}$ & $\mathbf{P}$ \\
\hline Step 1 & & & & \\
MASC total score & 0.95 & 0.43 & 2.24 & 0.04 \\
RADS/RCDS total score & -0.12 & 0.37 & -0.33 & 0.75 \\
Age & -2.21 & 1.79 & -1.24 & 0.24 \\
Sex & -24.53 & 9.96 & -2.46 & 0.03 \\
Pain intensity & 2.49 & 3.53 & 0.71 & 0.49 \\
Step 2 & & & & \\
MASC total score & 0.612 & 0.406 & 1.508 & 0.16 \\
RADS/RCDS total score & -0.155 & 0.325 & -0.476 & 0.64 \\
Age & -3.304 & 1.654 & -1.998 & 0.07 \\
Sex & -19.476 & 9.081 & -2.145 & 0.05 \\
Pain intensity & 0.025 & 3.314 & 0.007 & 0.99 \\
CASI total score & 1.59 & 0.73 & 2.17 & 0.05 \\
\hline
\end{tabular}

$R^{2}=0.71$ for step 1; Change in $R^{2}=0.12$ for step 2. CASI Childhood Anxiety Sensitivity Index; MASC Multidimensional Anxiety Scale for Children; RADS Reynolds Adolescent Depression Scale; RCDS Reynolds Child Depression Scale; SE Standard error

power of 0.2 , and that 100 participants would be required to demonstrate a power of 0.8 .

Unique contribution of anxiety sensitivity to fear of pain To examine the unique contribution of anxiety sensitivity to fear of pain, a hierarchical regression analysis was conducted, in which MASC total score, RADS total score, age, sex, pain intensity and CASI total score were the predictor variables, and PASS-20 total score was the dependent variable. Results of these analyses are presented in Table 4. Results indicated that $71 \%$ of the variance in fear of pain was accounted for by anxiety sensitivity, anxiety, depression, sex, age and pain intensity $\left(\mathrm{R}^{2}=0.71 ; \mathrm{F}[6,18]=4.87 ; \mathrm{P}=0.01\right)$. As shown in Table 4, after controlling for the effects of other potential predictors, anxiety sensitivity and (female) sex were the only significant predictors of increased levels of fear of pain. Anxiety sensitivity accounted for $12 \%$ of the unique variance in fear of pain scores.

Unique contribution of fear of pain to pain-related disability To examine the unique contribution of fear of pain to painrelated disability, a hierarchical regression analysis was conducted, in which MASC total score, RADS total score, age, sex, pain intensity and PASS-20 total score were the predictor variables, and FDI total score was the dependent variable. Results indicated that fear of pain was no longer a significant predictor of pain-related disability after controlling for anxiety, depression, sex, age and pain intensity $\left(R^{2}=0.53 ; F[6,18]=2.28\right.$; $\mathrm{P}=0.18)$ (Table 5).

\section{DISCUSSION}

The present study tested the hypothesis that fear of pain mediates the relationship between anxiety sensitivity and painrelated disability in children and adolescents with chronic pain. Results supported the first two steps of the mediation model, in that anxiety sensitivity predicted fear of pain and fear of pain predicted pain-related disability. However, anxiety sensitivity did not predict pain-related disability, and thus, the present results failed to support the proposed mediation model.
TABLE 5

Summary of hierarchical regression analysis for variables predicting pain-associated disability $(n=21)$

\begin{tabular}{lrrrr}
\hline Variable & $\boldsymbol{\beta}$ & SE $\boldsymbol{\beta}$ & $\boldsymbol{t}$ & $\mathbf{P}$ \\
\hline Step 1 & & & & \\
MASC total score & 0.95 & 0.43 & 2.22 & 0.05 \\
RADS/RCDS total score & -0.26 & 0.37 & -0.69 & 0.50 \\
Age & -0.51 & 1.80 & -0.28 & 0.78 \\
Sex & -12.90 & 10.05 & -1.28 & 0.22 \\
Pain intensity & -1.96 & 3.56 & -0.55 & 0.59 \\
Step 2 & & & & \\
MASC total score & 0.60 & 0.49 & 1.23 & 0.24 \\
RADS/RCDS total score & -0.21 & 0.36 & -0.58 & 0.57 \\
Age & 0.31 & 1.85 & 0.17 & 0.87 \\
Sex & -3.76 & 11.77 & -3.19 & 0.76 \\
Pain intensity & -2.89 & 3.51 & -0.82 & 0.43 \\
PASS-20 total score & 0.37 & 0.27 & 1.38 & 0.19 \\
\hline
\end{tabular}

$R^{2}=0.46$ for step 1; Change in $R^{2}=0.07$ for step 2. MASC Multidimensional Anxiety Scale for Children; PASS-20 Pain Anxiety Symptoms Scale-20; RADS Reynolds Adolescent Depression Scale; RCDS Reynolds Child Depression Scale; SE Standard error

Nevertheless, the relationships between each of the variables were in the proposed direction, and results were well in line with those of previous studies in adult chronic pain populations and healthy adolescents indicating that anxiety sensitivity is positively and substantially related to fear of pain $(10,11,14,16)$. Furthermore, the results of the present study demonstrated that fear of pain was positively and substantially related to disability. Therefore, the present findings suggest that anxiety sensitivity and fear of pain may each play a role in the processes that maintain chronic pain in children.

These preliminary data indicate that anxiety sensitivity predicts fear of pain and that fear of pain predicts disability. It is not obvious from these results whether anxiety sensitivity or fear of pain is the better variable to target in treatments designed to reduce disability. Anxiety sensitivity has been conceptualized as a trait vulnerability factor (6) from which fear of pain develops. As such, it may be a more reliable and consistent early predictor of increased disability, in that anxiety sensitivity may predict which children are more likely to develop fear and avoidance of their pain. However, relatively little is known about the developmental progression and consistency of anxiety sensitivity scores in children and adolescents over time, and it is possible that anxiety sensitivity changes as a function of specific anxiety-related life experiences as children develop and mature. In a large test-retest study of anxiety sensitivity in 2365 adolescents, Weems et al (30) examined the intercorrelations of anxiety sensitivity across a four-year span, and found evidence for both a predispositional trait model and a learning model of anxiety sensitivity. Weems and colleagues concluded that the interactive or combined effects of learning history and disposition may play a role in the development of anxiety sensitivity. Therefore, longitudinal studies of children and adolescents with chronic pain are needed to determine the extent to which anxiety sensitivity is stable over time. In addition, controlled intervention trials designed to treat anxiety sensitivity would help to address the issue of the modifiability of anxiety sensitivity as children and adolescents develop and mature.

Conversely, independent of the extent to which anxiety sensitivity is a stable trait or a learned response, it may be more 
logical for treatments to reduce fear of pain because (at least as conceptualized by fear-avoidance models) it is the most proximal predictor of disability, and as such, reductions in fearful behaviour and cognitions may have the greatest impact on pain-related disability scores in children and adolescents.

Investigation into the impact of anxiety sensitivity, fear of pain and avoidance behaviours on distress and disability in chronic pain is in its infancy. Research studies are needed to further investigate the fear-avoidance model in children with chronic pain, and to determine whether anxiety sensitivity is a reliable predictor of fear of pain and avoidance. The results of the present study found that, with the exception of sex, anxiety sensitivity was the only significant predictor of fear of pain after controlling for the effects of anxiety, depression, age and pain intensity. The effect of sex on fear of pain reflects the fact that girls reported higher fear of pain scores than boys. These findings may be indicative of sex differences in the reporting of anxiety and fear, in that girls may be more willing to express fear than boys; however, it is also important to note that these findings may have been influenced by the uneven distribution of boys and girls in the study sample. While the present results indicate that anxiety sensitivity accounts for a significant and unique proportion of the variance in fear of pain, the relationship between these two variables may be influenced by other factors that were not measured in the present study. As Muris and colleagues (16) have suggested, individuals who regularly experience pain may be more likely to develop fear of pain than those who do not regularly experience pain. Furthermore, although fear of pain may be an important predictor of painrelated disability, this relationship was no longer significant after accounting for the effects of other predictors (ie, anxiety, depression, sex, age and pain intensity), supporting the idea that children's pain-related disability is influenced by multiple factors.

The present study has several limitations. First, failure to observe the mediating effects of fear of pain may be due to a lack of power resulting from a small sample size. However, it is important to note that the present sample size had enough power to detect two significant bivariate relationships (between CASI and PASS-20, and PASS-20 and pain-related disability, accounting for $39 \%$ and $40 \%$ of the variance, respectively). Power analysis indicated that 100 participants would be needed to demonstrate that fear of pain mediates the relationship between anxiety sensitivity and pain-related disability. Future research with a larger sample size is needed before definitive conclusions can be drawn about the proposed mediation model. Second, the regression analyses examining the unique contributions of anxiety sensitivity to fear of pain, and of fear of pain to disability should be interpreted with caution due to the small case to variable ratio. Future research with a larger sample is needed to determine the extent to which the observed correlations and regression coefficients are reproducible.

Another drawback of the present study is the cross-sectional design. As such, the direction of influence between anxiety sensitivity and fear of pain remains unclear. Experimental or longitudinal studies are needed to determine whether causal links exist between these two variables. It should be noted that the lack of prior investigations into fear-avoidance models in children may be due, in part, to the fact that valid and reliable questionnaires have not been developed to measure fear of pain in children. A well-validated measure of fear of pain is needed so that this distinct psychological construct can be accurately measured in children and adolescents, and so that comparisons can be made across studies. The modified version of the PASS used in the present study demonstrated good internal consistency $(\alpha=0.89)$. However, these data need to be replicated in a larger sample using a validated version of the PASS with the modifications for children used in the present study.

Furthermore, it is important to note that the present study relied on self-report data. To minimize the influence of potential response biases, future studies may wish to obtain corroborative evidence from parent ratings, as well as behavioural measures of pain avoidance and disability. In addition, it is possible that the relationships observed in the present study may be related to the study sample, which consisted of children who continued to experience chronic pain an average of three years following discharge from the pain management clinic. It would be interesting to investigate the relationships among these constructs in children and adolescents when they are first admitted to the clinic to examine the generalizability of these findings.

\section{CONCLUSIONS}

The results of the present study indicate that anxiety sensitivity may be a vulnerability factor that increases disability via its effects on fear of pain. That is, children high in anxiety sensitivity appear to have a higher fear of pain, which, in turn, is linked to an increase in pain-related disability. Treatments designed to target fear responses to pain may help to prevent or reduce pain-related disability in children and adolescents with chronic pain.

ACKNOWLEDGEMENTS: Supported by New Emerging Team Grant GHL-63209 from the Institute of Gender and Health, Canadian Institutes of Health Research, awarded to Dr Patricia McGrath. Dr Joel Katz is supported by a Canada Research Chair in Health Psychology at York University. This paper is derived, in part, from Andrea Martin's Master's thesis.

\section{REFERENCES}

1. Perquin CW, Hazebroek-Kampschreur AA, Hunfeld JA, et al. Pain in children and adolescents: A common experience. Pain 2000;87:51-8.

2. El-Metwally A, Salminen JJ, Auvinen A, Kautiainen H, Mikkelsson M. Prognosis of non-specific musculoskeletal pain in preadolescents: A prospective 4-year follow-up study till adolescence. Pain 2004;110:550-9.

3. Eccleston C, Crombez-G, Scotford A, Clinch J, Connell H. Adolescent chronic pain: Patterns and predictors of emotional distress in adolescents with chronic pain and their parents. Pain 2004;108:221-9.

4. Asmundson GJ, Norton PJ, Norton GR. Beyond pain: The role of fear and avoidance in chronicity. Clin Psychol Rev 1999;19:97-119.

5. Reiss S. The expectancy model of fear, anxiety, and panic. Clin Psychol Rev 1991;11:141-53.

6. Turk DC. A diathesis-stress model of chronic pain and disability following traumatic injury. Pain Res Manage 2002;7:9-19.

7. Vlaeyen JWS, Linton SJ. Fear-avoidance and its consequences in chronic musculoskeletal pain: A state of the art. Pain 2000;85:317-32.

8. Asmundson GJ, Norton PJ, Veloso F. Anxiety sensitivity and fear of pain in patients with recurring headaches. Behav Res Ther 1999;37:703-13.

9. Norton PJ, Asmundson GJ. Anxiety sensitivity, fear, and avoidance behavior in headache pain. Pain 2004;111:218-23

10. Asmundson GJ, Norton GR. Anxiety sensitivity in patients with physically unexplained chronic back pain: A preliminary report. Behav Res Ther 1995;33:771-7. 
11. Asmundson GJ, Taylor S. Role of anxiety sensitivity in pain-related fear and avoidance. J Behav Med 1996;19:577-86.

12. Peterson RA, Reiss S. Anxiety Sensitivity Index Manual. Orland Park: International Diagnostic Systems Inc, 1987.

13. McCracken LM, Zayfert C, Gross RT. The Pain Anxiety Symptoms Scale: Development and validation of a scale to measure fear of pain. Pain 1992;50:67-73

14. Zvolensky MJ, Goodie JL, McNeil DW, Sperry JA, Sorrell JT. Anxiety sensitivity in the prediction of pain-related fear and anxiety in a heterogeneous chronic pain population. Behav Res Ther 2001;39:683-96.

15. McCracken LM, Gross RT, Sorg PJ, Edmands TA. Prediction of pain in patients with chronic low back pain: Effects of inaccurate prediction and pain-related anxiety. Behav Res Ther 1993;31:647-52.

16. Muris P, Vlaeyen J, Meesters C. The relationship between anxiety sensitivity and fear of pain in healthy adolescents. Behav Res Ther 2001;39:1357-68

17. Muris P, Vlaeyen JW, Meesters C, Vertongen S. Anxiety sensitivity and fear of pain in children. Percept Mot Skills 2001;92:456-8.

18. Martin AL, McGrath PA, Brown SC, Katz J. Children with chronic pain: Impact of sex and age on long-term outcomes. Pain 2007;128:13-9.

19. Silverman WK, Fleisig W, Rabian B, Peterson RA. Childhood Anxiety Sensitivity Index. J Clin Child Psychol 1991;20:162-8.

20. McCracken LM, Dhingra L. A short version of the Pain Anxiety Symptoms Scale (PASS-20): Preliminary development and validity. Pain Res Manage 2002;7:45-50.

21. Walker LS, Greene JW. The functional disability inventory: Measuring a neglected dimension of child health status. J Pediatr Psychol 1991;16:39-58.
22. March JS, Parker JD, Sullivan K, Stallings P, Conners CK. The Multidimensional Anxiety Scale for Children (MASC): Factor structure, reliability, and validity. J Am Acad Child Adolesc Psychiatry 1997;36:554-65.

23. Reynolds WM. Reynolds Child Depression Scale: Professional Manual. Lutz: Psychological Assessment Resources, 1989:iii-55.

24. Reynolds WM. Reynolds Adolescent Depression Scale: Professional Manual. Lutz: Psychological Assessment Resources, 2002:ii-172.

25. Kashikar-Zuck S, Vaught MH, Goldschneider KR, Graham TB, Miller JC. Depression, coping, and functional disability in juvenile primary fibromyalgia syndrome. J Pain 2002;3:412-9.

26. Walker LS, Smith CA, Garber J, Claar RL. Testing a model of pain appraisal and coping in children with chronic abdominal pain. Health Psychol 2005;24:364-74.

27. Reid GJ, McGrath PJ, Lang BA. Parent-child interactions among children with juvenile fibromyalgia, arthritis, and healthy controls. Pain 2005;113:201-10

28. Lynch AM, Kashikar-Zuck S, Goldschneider KR, Jones BA. Psychosocial risk for disability in children with chronic back pain. J Pain 2006;7:244-51.

29. Baron RM, Kenny DA. The moderator-mediator variable distinction in social psychological research: Conceptual, strategic, and statistical considerations. J Pers Soc Psychol $1986 ; 51: 1173-82$

30. Weems CF, Hayward C, Killen J, Taylor CB. A longitudinal investigation of anxiety sensitivity in adolescence. J Abnorm Psychol 2002;111:471-7. 


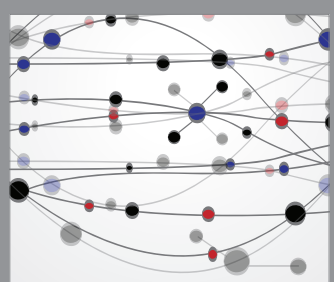

The Scientific World Journal
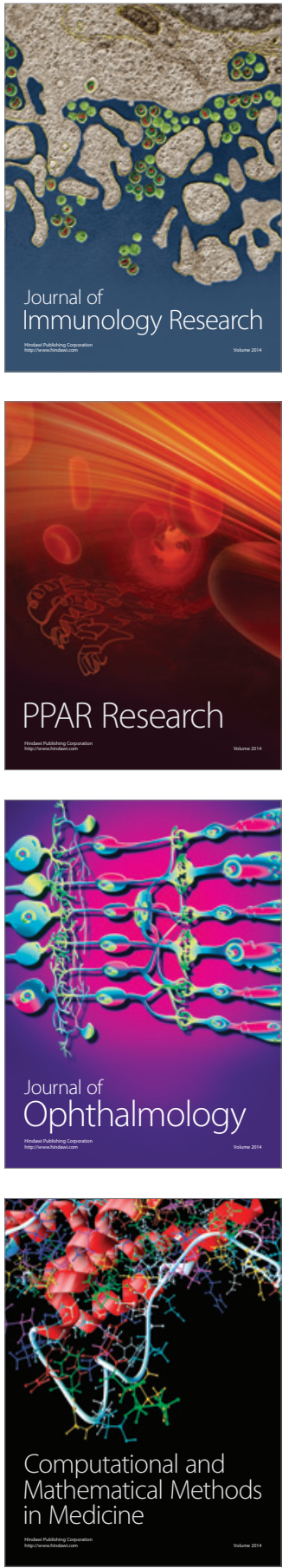

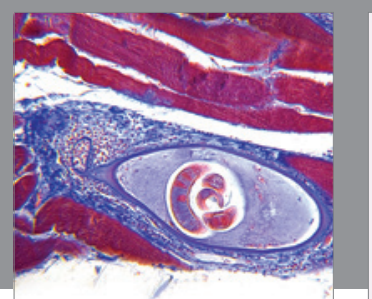

Gastroenterology Research and Practice

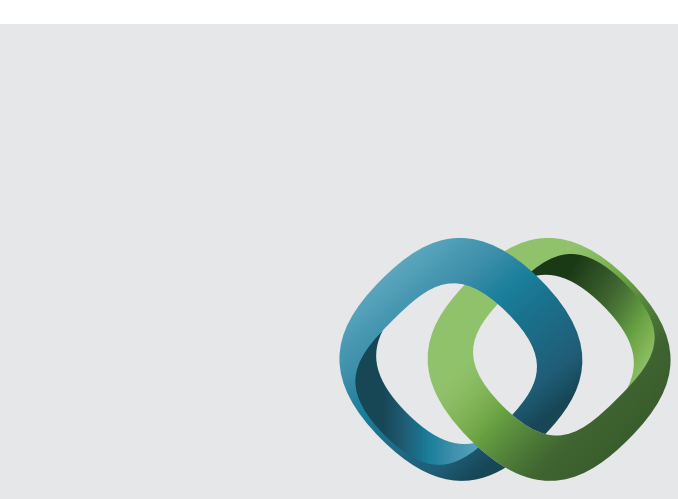

\section{Hindawi}

Submit your manuscripts at

http://www.hindawi.com
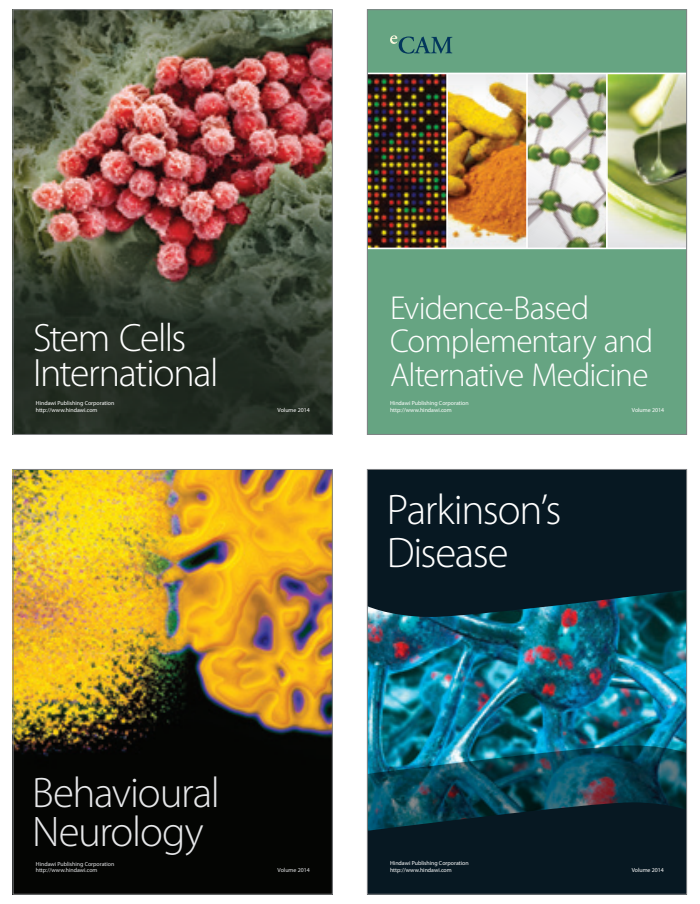
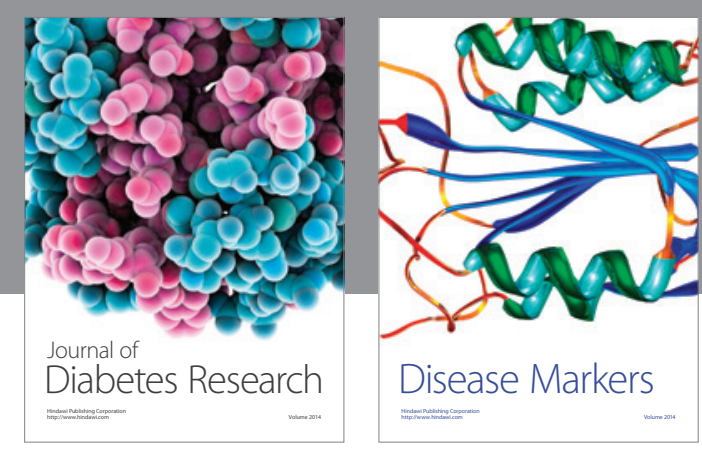

Disease Markers
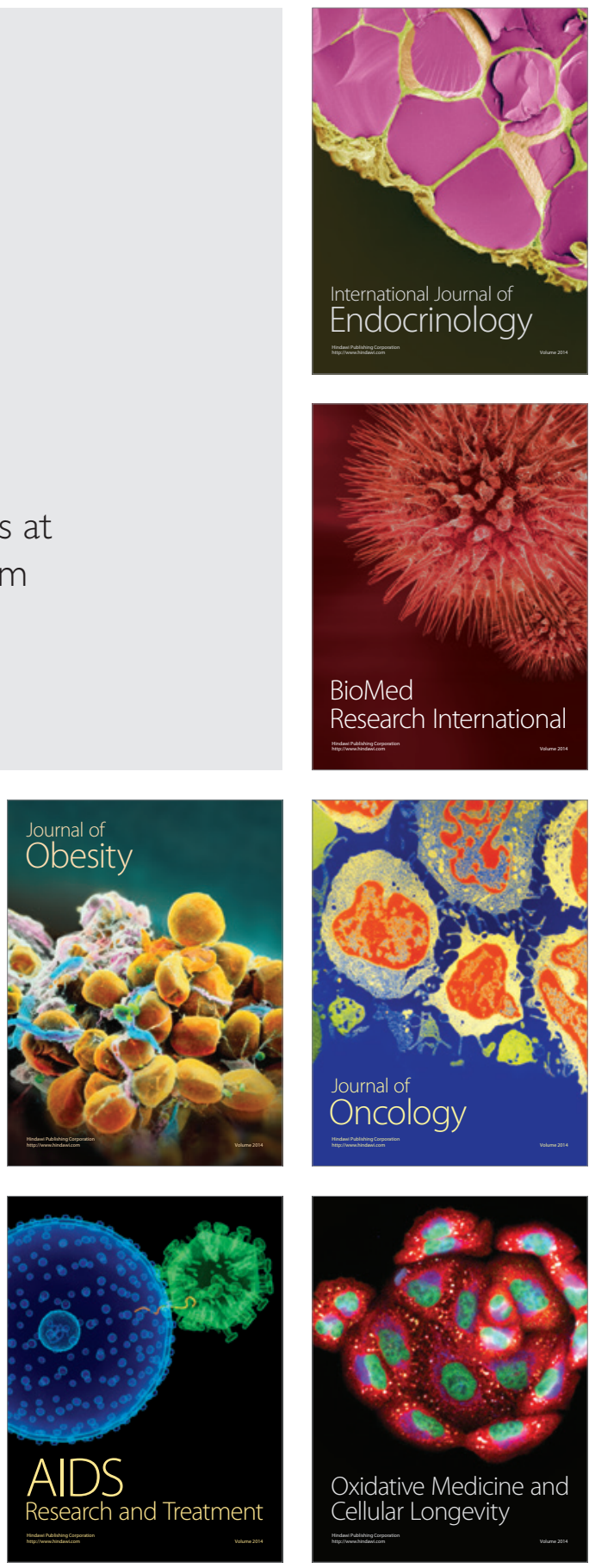